\title{
GBEP
}

\section{O currículo de cursos técnicos de lazer no Brasil: um estudo de caso da formação profissional}

Carla Augusta Nogueira Lima e Santos

Hélder Ferreira Isayama

\section{Resumo}

Objetiva diagnosticar e analisar o perfil de formação profissional, por meio do estudo de caso do Centro de Educação Profissional do Amapá (Cepa), que oferece curso técnico em lazer. O percurso metodológico combinou pesquisa bibliográfica, documental e de campo. A pesquisa documental se baseou na análise de projetos político-pedagógicos da instituição e do curso. Na pesquisa de campo, utilizamos a técnica de entrevista semiestruturada com nove docentes e com o coordenador do curso técnico em lazer. Com base nas análises, percebemos que o Cepa apresenta como objetivo a ideia de formar técnicos em lazer para atenderem a demanda do mercado, no entanto, foi possível observar que a abordagem atribuída a essa área não se restringe ao conceito de "mercadoria a ser consumida". Nesse sentido, identificou-se uma preocupação em produzir e ministrar conhecimentos para além das competências técnicas no intuito de uma formação mais cidadã. O perfil do profissional formado contempla saberes teórico-práticos num viés multidisciplinar, na tentativa de qualificar os discentes para intervirem em diferentes espaços de vivência do lazer.

Palavras-chave: lazer; formação profissional; ensino técnico; currículo. 


\section{Abstract \\ The curriculum of technical leisure courses in Brazil: a case study of professional training}

This research focused on the diagnostic and analysis of the profile of professional training. A case study of the Centro de Educação Profissional do Amapá (Сepa), which offers a technical leisure course, was conducted. The methodology used combined bibliographic, documentary and field research. The documentary research was based on the analysis of political pedagogical projects of the institution and its course. Semi-structured interviews with nine teachers and the coordinator of the technical leisure course were carried out in the field research. Based on the analyses, we noticed that Cepa has the idea of training leisure technicians to meet the market demand as a goal; however, it was noticeable that the approach used in leisure is not restricted to the concept of "commodity to be consumed". Consequently, a concern about producing and providing knowledge that goes beyond technical competences was identified in the intent to form students as citizens. The profile of the graduated professional included theoretical and practical knowledge in a multidisciplinary way, as an attempt to qualify students to intervene in different spaces, where leisure can be experienced.

Keywords: leisure; professional training; technical course; curriculum.

\section{Introdução}

$\mathrm{Na}$ atualidade, são crescentes as possibilidades de formação profissional em lazer e, conforme Gomes e Melo (2003), essas oportunidades estão vinculadas ao "promissor" mercado nessa área. Segundo Isayama (2005), existe uma tendência à comercialização das propostas de formação profissional, e o lazer é focalizado como um filão do mercado que abre grandes possibilidades de lucro. Assim, com a expansão do fenômeno lazer e suas respectivas possibilidades de atuação, surgem as mais diversas ações de formação para capacitar profissionais como forma de suprir a demanda do mercado.

Além de grupos de estudo/pesquisa, eventos técnico-científicos, publicações de artigos específicos sobre lazer e criação de listas de discussão e blogs na internet, configuram-se como espaços de formação profissional em lazer os diferentes cursos de capacitação, qualificação, graduação e pós-graduação, bem como os de nível técnico. Tais possibilidades variam em termos de formato, carga horária, método, conteúdo e objetivo. 
Em cada uma das possibilidades, existe um currículo que se configura com base em conflitos culturais entre diferentes sujeitos. Assim, compartilhamos da ideia de que o currículo é "um artefato sempre envolvido com relações de poder, um texto que governa condutas e que produz sujeitos de determinados tipos" (Paraíso, 2010, p. 30). O currículo é fruto de uma invenção social e cultural, não descontextualizado historicamente. É um discurso em que podemos identificar os conhecimentos como "campos culturais, como campos sujeitos à disputa e à interpretação, nos quais os diferentes grupos tentam estabelecer sua hegemonia" (Silva, 2009, p. 135).

Entendemos o currículo como algo além de um conjunto de disciplinas determinadas por procedimentos, objetivos e métodos, pois é certo que ele é permeado de intencionalidades que determinam e selecionam saberes. Nesse contexto, ao analisar questões curriculares referentes aos cursos técnicos de lazer, buscamos olhar "além da moldura", na tentativa de compreender a formação profissional, bem como identificar os saberes selecionados que compõem o currículo desses espaços de formação.

Vale ressaltar que, no Brasil, a denominada Educação Profissional e Tecnológica apresenta possibilidades de formação em lazer em três diferentes níveis: 1) formação inicial e continuada ou qualificação profissional; 2) educação profissional técnica de nível médio; e 3) educação tecnológica de graduação e pós-graduação. Perante o universo de oportunidades, delimitamos como foco desta pesquisa os cursos de nível técnico que apresentam carga horária mínima de 800h e podem acontecer de forma integrada, subsequente ou concomitante. São três as instituições reconhecidas pelo Ministério da Educação (MEC) que possibilitam a formação em lazer no nível técnico.

Na tentativa de definir o que seria um "técnico", Maia (2003, p. 83) afirma que é aquele que possui a virtude de "dominar assuntos e de ser profundo conhecedor das técnicas de resoluções de problemas. Portanto, um técnico na essência da palavra". A denominação atribuída pelo autor ao profissional técnico pode nos parecer confusa se considerarmos, por exemplo, que a graduação também visa formar um sujeito que domine determinado assunto e seja detentor/conhecedor de técnicas específicas para o exercício de sua profissão. Portanto, ao falar de um profissional técnico, estamos nos referindo àquele que possui uma formação com o foco no mercado de trabalho e em curto prazo (entre 800 e 1.200 horas), o que possibilita uma rápida inserção nesse espaço, ao contrário do graduado, que possui uma formação mais abrangente devido ao maior tempo de formação (4 a 6 anos), tendo a oportunidade de ir além do ensino, privilegiando, também, a pesquisa e a extensão. Além disso, essa modalidade oferece aos profissionais em formação a oportunidade de aprofundarem os conhecimentos mediante ingresso em cursos de pósgraduação stricto ou lato sensu e também pode possibilitar a carreira de docência em cursos superiores.

É pertinente frisar que os cursos que formam profissionais em lazer, assim como outros cursos técnicos no Brasil, por se apresentarem com 
nomenclaturas variadas, tiveram o ano de 2009 para se adequarem ao novo catálogo do Ministério da Educação, não só em termos de nome como também de formato. Para tanto, o MEC desenvolveu uma tabela de convergência, no sentido de orientar os cursos com denominações variadas a adotarem a nomenclatura única de "técnico em lazer":

A seleção do que faria parte ou não das orientações curriculares dos cursos pertencentes ao eixo "Hospitalidade e Lazer" baseou-se em um perfil profissional almejado, que fundamentou a escolha e a hierarquização dos conhecimentos a serem transmitidos e discutidos no interior dos currículos em questão. Nesse sentido, as questões "Que profissional deve ser formado?" e "O que deve ser ensinado?" serviram como norte para o processo de construção curricular.

Portanto, é importante compreender que essa organização curricular parte de um pressuposto: o que são e o que fazem esses profissionais? No caso do profissional do lazer, as pré-concepções, muitas vezes, recaem sobre o senso comum. Dessa forma, o currículo é direcionado para formar profissionais que cumpram/assumam esses pré-requisitos. Infelizmente, encontramos ainda aqueles que acreditam que essas funções/ações do profissional de lazer devam se fundamentar pela intuição, pelo amadorismo e pelo improviso. Afinal, o pensamento é de que se trata de um trabalho "cinco estrelas" de fácil atuação, aberto a todos os interessados, mesmo os sem qualquer qualificação (Stoppa, 2000). Porém, o que se pode constatar é que a maioria dos profissionais de lazer é submetida a extensas jornadas de trabalho com horário de descanso reduzido, sem contar a sobrecarga advinda do número insuficiente de profissionais na equipe de trabalho, acarretando desgaste físico, intelectual e emocional.

Nos debates sobre a formação profissional em lazer, observamos críticas como a de Marcellino (2003), que considera que, na maior parte das vezes, os cursos que abordam a temática "lazer" são baseados numa visão abstrata desse tema, buscando habilitar um "especialista tradicional". O autor afirma ainda que "quase sempre é o mercado o regulador do tipo de profissional." (Marcellino, 2003, p. 10).

Além disso, pensamos a atuação nesse campo como algo complexo que demanda competência técnica, sensibilidade e compromisso político como embasamento para uma intervenção crítica e criativa na busca da emancipação dos sujeitos. Porém, a visão de senso comum acaba por marginalizar a ação do profissional de lazer, e essa desvalorização, tanto em termos de reconhecimento quanto da questão financeira, estabelece uma seleção e, consequentemente, uma atuação calcada em estereótipos. Segundo Stoppa (2000, p. 178), o que prevalece "é um profissional com um estereótipo voltado para uma pessoa bem apessoada, alegre e que gosta de criança". Pinto (2001) alerta que para esses profissionais não basta ter animação, bom senso, talento, tampouco saber conteúdos, dominar técnicas e ter experiências, é preciso ampliar e qualificar esse perfil para que se possam propagar as vivências culturais em busca de transformação sociocultural e de inclusão social.

Assim, ao trazer para análise os cursos de nível técnico que formam profissionais para atuarem no âmbito do lazer, colocamos em evidência 
não só seu currículo, como também o perfil profissional que se pretende formar. A partir disso, questionamos: Que profissional tem sido formado nos cursos técnicos de lazer? Quais conhecimentos dessa área têm sido selecionados, priorizados e enfatizados?

Este estudo teve, portanto, o objetivo de diagnosticar e analisar o perfil de formação profissional proposto por uma instituição que oferece o curso técnico em lazer. Na tentativa de compreender o que o currículo pretende e o que o influenciou, buscou-se identificar como se dá o trato com o lazer e quais saberes e competências têm sido enfatizados na construção desse currículo. Trata-se, portanto, de estudo de caso que investigou uma instituição situada na cidade de Macapá, no Estado do Amapá, que possui um dos três cursos técnicos em lazer credenciados pelo MEC. A escolha dessa instituição se justifica pelo fato de ser a única a responder o convite para participar da pesquisa.

\section{Metodologia}

O estudo consistiu em pesquisa bibliográfica, documental e de campo. A pesquisa bibliográfica teve como eixo estudos referentes aos temas lazer, formação profissional, currículo e educação profissional. Para pesquisa documental, tivemos acesso ao projeto político-pedagógico da instituição (Amapá, 2007) e ao projeto político-pedagógico do curso técnico em lazer (Amapá, 2010).

Na pesquisa de campo, realizamos entrevista semiestruturada com o coordenador e os demais professores responsáveis pelas disciplinas do curso. A escolha desses sujeitos se deve ao fato de exercerem papéis centrais nas questões curriculares, pois são eles os responsáveis por criar, organizar e modificar o currículo. Os nove professores entrevistados foram selecionados pelos critérios de acessibilidade e disponibilidade, visto que a instituição apresenta uma considerável rotatividade do corpo docente.

Na tentativa de compreender o perfil de formação profissional proposto pelo Cepa, foram extraídas as seguintes categorias de análises: estrutura curricular: organização, modificações e funcionamento; perfil profissional almejado; perfil do corpo docente; concepção de lazer e concepção do profissional de lazer; e relações teoria e prática. Os dados coletados foram examinados com base na técnica de análise de conteúdos proposta por Triviños (1987).

\section{Educação profissional: escolha, ênfase e poder nos currículos dos cursos técnicos}

Sobre a educação profissional, entendemos que sempre esteve ligada ao contexto e ao momento vivido - ora para evitar vícios, para produzir mão de obra, ou a serviço de algo ou alguém -, ou seja, o caráter assistencialista das políticas de educação sobrepunha uma suposta 
preocupação do ensino profissional com a formação dos sujeitos. O interesse maior era, num primeiro momento, o cuidado higienista num viés moral e, posteriormente, o interesse de atender a demanda do mercado produzindo força de trabalho.

A partir das transformações ocorridas no mundo do trabalho e no momento social, político e econômico, cria-se a Lei de Diretrizes e Bases da Educação Nacional (LDB) - Lei no 4.024, de 20 de dezembro de 1961 -, que determinava a equivalência de cursos profissionalizantes e propedêuticos para prosseguimento nos cursos superiores (Kruger; Tambara, 2006). A integração dos cursos e o posterior investimento do governo nesse setor garantiam qualidade na educação, o que despertou o interesse da população de classe média por essas escolas a título de ingresso na universidade. Buscava-se ensino gratuito e de qualidade não para exercer alguma profissão técnica, mas sim para fins de acesso ao ensino superior.

Contudo, a Lei $\mathrm{n}^{\circ}$ 5.692, de 11 de agosto de 1971, elaborada no governo Médici, foi além e propôs a profissionalização universal do $2^{\circ}$ grau, ou seja, os cursos profissionalizantes deixariam de ser opção e se tornariam obrigatórios, tendo como justificativa a falta de técnicos no mercado. Com a profissionalização universal, o currículo do ensino médio ficou descaracterizado, e o $2^{\circ}$ grau já não mais focava o ensino propedêutico, pois se juntaram a ele diversas disciplinas de caráter profissionalizante. Essa ideia ocorreu em um momento em que o "Brasil objetivava participar da economia internacional e, neste sentido, delegou (entre outras coisas) ao sistema educacional a atribuição de preparar os recursos humanos para a absorção do mercado de trabalho" (Manfredi, 2002, p. 105).

Com a promulgação da Lei $n^{0}$ 7.044, de 18 de outubro de 1982, a profissionalização obrigatória é excluída da estrutura do ensino médio regular, porém permanece a integração do ensino técnico com o médio.

No intuito de oferecer cursos técnicos àqueles que realmente pretendiam exercer suas habilidades técnicas no mercado de trabalho, foi implantada a Reforma do Ensino Técnico por meio do Decreto no 2.208, de 17 abril de 1997, que compunha a LDB de dezembro de 1996. Tal decreto visava revogar a integração e, consequentemente, separar o ensino médio do profissional. Apresentam-se, assim, dois grupos distintos: o que procura o ensino profissional para desenvolver habilidades técnicas e o que busca o ensino médio como preparação para o ensino superior.

A Reforma do Ensino Técnico foi transparente ao entender a formação no ensino profissional como um processo meramente técnico, visando ao "domínio das técnicas de execução de atividades e tarefas, no setor produtivo e de serviços" (Oliveira, 2000, p. 42). Assim, na maioria das vezes o técnico é relacionado à parte prática do cumprimento de tarefas, à prestação de serviços e ao trabalho manual/braçal, diferentemente dos profissionais de curso superior, voltados para o trabalho de orientar, fiscalizar, organizar, criar, avaliar, ou seja, mais vinculados ao trabalho intelectual. 
Kuenzer (1999) considera que os binômios intelectual-braçal/teóricoprático são frutos do entendimento de que para o ensino profissional basta uma formação parcial com foco no aprendizado rigoroso de procedimentos a serem repetidos e memorizados. Segundo a autora, é preciso romper com a perspectiva de que, no trabalho de natureza operacional, não há necessidade de escolarização ampliada, uma vez que não há necessidades significativas de trabalho intelectual nesse nível.

No entanto, as relações do ensino técnico com o mercado estão cada vez mais expressivas, pois o objetivo é formar o indivíduo para atender a demanda do mercado. Para isso, devem-se formar, de forma prática e rápida, indivíduos técnicos o suficiente para preencherem a realidade do mercado de trabalho. A proliferação de escolas de cursos técnicos é acompanhada de propagandas que evidenciam essa estreita relação. Anúncios como "o mercado está esperando por você", "prepare-se para o mercado" e "seu emprego está aqui" revelam uma formação meramente técnica voltada para o domínio de determinadas habilidades para execução de tarefas e serviços no setor produtivo. É o mercado determinando o ensino.

Nesse sentido, Oliveira (2000, p. 42) alerta para essa relação educação/mercado e defende que "a educação não seja equacionada nos limites da modernização econômica do país e dos interesses empresariais, reduzindo direitos à educação aos imperativos do mercado de trabalho".

Ferreti (apud Brasil, 1996) deixa clara a íntima relação entre as demandas econômicas e a educação profissional, afinal essa é uma das proposições da LDB ao ressaltar o "domínio dos princípios científicos e tecnológicos que presidem a produção moderna". No entanto, é preciso atentar para essa supervalorização, que pode acarretar outras mudanças diante dos interesses produtivos.

As mudanças nas leis da educação profissional não cessaram com a Reforma do Ensino Técnico de 1997. Em julho de 2004, criou-se o Decreto $\mathrm{n}^{\mathrm{o}} 5.154$, de 23 de julho de 2004, para novamente integrar os ensinos técnico e médio. Essa articulação aconteceu de três formas:

I - integrada, oferecida somente a quem já tenha concluído o ensino fundamental, sendo o curso planejado de modo a conduzir o aluno à habilitação profissional técnica de nível médio, na mesma instituição de ensino, contando com matrícula única para cada aluno;

II - concomitante, oferecida somente a quem já tenha concluído o ensino fundamental ou esteja cursando o ensino médio, na qual a complementaridade entre a educação profissional técnica de nível médio e o ensino médio pressupõe a existência de matrículas distintas para cada curso, podendo ocorrer:

a) na mesma instituição de ensino, aproveitando-se as oportunidades educacionais disponíveis;

b) em instituições de ensino distintas, aproveitando-se as oportunidades educacionais disponíveis; ou

c) em instituições de ensino distintas, mediante convênios de intercomplementaridade, visando ao planejamento e ao desenvolvimento de projetos pedagógicos unificados;

III - subsequente, oferecida somente a quem já tenha concluído o ensino médio. (Brasil, 2004). 
Kruger e Tambara (2006) consideram essa reintegração um retrocesso, pois muda o foco de ensinar habilidades técnicas àqueles que desejam ingressar no mercado de trabalho em função da preparação para o vestibular. Por outro lado, consideramos importante a ampliação dos conhecimentos da educação profissional para além das competências e habilidades técnicas. A formação geral integrada à formação técnica é fundamental, pois, assim como Oliveira (2000), acreditamos que a integração proporciona domínio das bases tanto científicas e tecnológicas quanto sócio-históricas que presidem o contexto dos sujeitos envolvidos no processo de formação.

Contudo, assim como Maia (2003, p. 97), apostamos em um processo de ensino técnico calcado em "um permanente questionar, refletir, recuar e avançar em busca de novos horizontes" para reverter esse quadro; afinal de contas, o "processo educativo é dinâmico e surpreendente". Os debates apresentados sobre o ensino profissionalizante nos deram pistas para entender limites, desafios e características da formação do profissional em lazer em nível técnico, com base na pesquisa de campo realizada.

\section{O curso de técnico em lazer do Centro de Educação Profissional do Amapá}

De acordo com o PPP-Instituição, o Centro de Educação Profissional do Amapá é mantido pelo governo do Estado e pertence à rede oficial de ensino da Secretaria de Estado da Educação (Seed). Foi criado pelo Decreto $n^{\circ}$ 987, de 16 de março de 2000, e teve seu funcionamento autorizado por meio da Portaria Seed $n^{\circ} 668$, de 30 de julho de 2001. Os primeiros cursos ofertados foram o de técnico em informática e de técnico em turismo. No ano de 2004, foi implantado o curso de técnico em hotelaria e, em 2007, foram criados os cursos de técnico de informática para a internet e de técnico de ecoturismo e lazer.

Porém, diante das reformulações decretadas pelo MEC em 2009, a instituição teve que se adequar às nomenclaturas e à organização curricular de acordo com o novo catálogo da educação profissional. Dessa forma, alguns cursos foram desmembrados e outros extintos, acarretando uma nova configuração. São ofertados, hoje, cursos dos eixos tecnológicos de informática e de hospitalidade e lazer. No eixo tecnológico de informática, são ofertados os cursos técnicos de: manutenção e suporte; redes de computadores; e informática para internet. No eixo tecnológico de hospitalidade e lazer, são ofertados os cursos técnicos de: eventos; guia de turismo; agenciamento de viagens; cozinha; e lazer.

\section{Estrutura curricular: organização, modificações e funcionamento}

Antes das reformulações estabelecidas pelo MEC, a instituição, assim como outras escolas de ensino profissional, ofertava cursos de caráter 
amplo e generalista, como o de técnico em ecoturismo e lazer. Com base no PPP desse antigo curso, encontramos a seguinte formatação curricular: módulo I - básico sem terminalidade; módulo II - gestão de ecoturismo; módulo III - gestão de lazer e recreação; módulo I + módulo II + módulo III: técnico em ecoturismo e lazer.

A divisão em módulos permitia a formação intermediária, ou seja, o aluno cursava três módulos: após o módulo I, que era o básico, cursava o módulo II - gestão de ecoturismo. Dessa forma, se o aluno optasse por sair do curso após o segundo módulo, teria uma qualificação intermediária de gestor em ecoturismo. Aqueles que optassem por finalizar o curso fariam o módulo III - gestão de recreação e lazer -, conseguindo, ao final, a certificação de técnico em ecoturismo e lazer.

Como podemos perceber, diante do novo catálogo da educação profissional, os cursos foram desmembrados e ficaram mais específicos. Sobre essa nova configuração, o entrevistado 2 afirmou:

Tenho algumas críticas. Da forma como estava, ele dava mais condições de empregabilidade. E, como desmembrou, só está dando um segmento de empregabilidade para a pessoa. Agora só tem uma opção. E considerando a questão nossa - que se chama 'maiores condições de empregabilidade' -, eu diria que era melhor como estava.

No caso específico da instituição, acreditamos que esse desmembramento proporcionado pelo MEC aconteceu mais no âmbito estrutural e de nomenclatura, pelo menos no que diz respeito à mudança do curso de técnico em ecoturismo e lazer para o de técnico em lazer. Afinal, comparando os dois PPPs, percebemos que o texto é idêntico, havendo apenas a retirada do termo "ecoturismo" do PPP vigente e de expressões do tipo: "desenvolvimento sustentável", "recursos naturais" e "impacto ambiental". Até mesmo a justificativa do projeto do curso de técnico em lazer é baseada nas potencialidades ecoturísticas do Estado:

O Estado apresenta uma mega biodiversidade com grandes áreas de seu território intactas. Apresenta cenários belíssimos e diversificados como as florestas, as praias e manguezais, a pororoca, os campos de várzea, o rio Amazonas, o maior rio do mundo em volume d'água, que banha com exclusividade Macapá. (Amapá, 2007, p.4).

Isso mostra que a modificação a partir do novo catálogo do MEC/2009 ficou mais no âmbito estrutural. O fato de o PPP antigo ter vários conteúdos em comum com o atual - como perfil profissional, objetivo, justificativa, entre outros - confere ao técnico em lazer formação e, consequentemente, atuação bem próximas das de um técnico em ecoturismo e lazer. Porém, é preciso considerar que o tempo de formação no antigo curso era de 1.120 horas, diferentemente da carga horária atual, que é de 840 horas. Além disso, havia disciplinas mais específicas em relação ao ecoturismo, por exemplo, turismo de aventura e educação ambiental, legislação aplicada ao ecoturismo e técnicas de ecoturismo, além de conteúdos como técnicas para sobreviver na natureza ou técnicas de mergulho e voo livre. Mesmo 
aceitando a existência de tais especificidades, entendemos que a atuação do profissional formado apenas em técnico em lazer não está restrita ao desenvolvimento de ações relacionadas à natureza.

Outro ponto a ser ressaltado se refere à possibilidade de certificação intermediária do atual currículo de técnico em lazer, que se divide em módulos I e II. O primeiro possui carga horária de 440 horas e certifica o aluno como auxiliar de recreação; já o segundo módulo, com carga horária de 400 horas, confere ao aluno o título de monitor de lazer e recreação. Dessa forma, a matriz curricular observa a seguinte estrutura: módulo I: auxiliar de recreação; módulo II: monitor de lazer e recreação; módulo I + módulo II: técnico em lazer. A certificação intermediária é uma orientação do MEC, com base no Decreto no 5.154/2004 (Brasil, 2004).

No entanto, é preciso ficar atento a pelo menos dois fatores. Primeiro: qual a intenção dessa habilitação intermediária? Acreditamos que essa estrutura contempla a possibilidade de formação intermediária para atender tanto aos discentes quanto ao mercado de trabalho. Dessa forma, o aluno que optar por cursar o módulo I - ou que até mesmo não consiga ir adiante - já "garantirá" uma habilitação profissional, possibilitando seu ingresso no mercado de trabalho após um período de formação com carga horária de 440 horas. Esse imediatismo também vai ao encontro dos interesses dos empregadores que necessitam de mão de obra especializada em um curto período de formação. Essa hipótese pode ser identificada na fala de um dos entrevistados, quando perguntado sobre o funcionamento do curso em módulos:

O auxiliar de recreação é o aluno que conclui o primeiro módulo e, se ele não terminar o segundo módulo que lhe dá direito ao curso técnico em lazer, ele já sai capacitado para o mercado de trabalho como auxiliar de recreação. Se completar os dois módulos, ele sai com o curso técnico em lazer e com as especificações de auxiliar em recreação e monitor de lazer e recreação. A cada módulo tivemos que dar uma terminalidade para os alunos. Se não terminasse o curso, ele teria que ter uma qualificação para enfrentar o mercado de trabalho. (Entrevistado1).

O segundo fator se relaciona ao seguinte questionamento: qual a diferença, em termos de formação e atuação, entre um auxiliar de recreação e um técnico em lazer? É importante esclarecer que essa estrutura em módulos com certificação intermediária é uma sugestão do MEC e não uma obrigatoriedade; do mesmo modo, a instituição que optar por essa dinâmica tem a autonomia de atribuir o título de formação profissional que desejar para cada fase da formação. No caso específico do Cepa, o nome adotado foi o de "auxiliar de recreação"; assim, no que diz respeito à formação, existe uma diferença clara na matriz curricular, de forma que a carga horária e as disciplinas se diferenciam em cada módulo, da seguinte forma: 


\section{Quadro 1 - Grade Curricular referente ao Módulo I}

\begin{tabular}{|l|c|}
\hline \multicolumn{2}{|c|}{ I Módulo de Competências - Auxiliar de Recreação } \\
\hline \multicolumn{1}{|c|}{ Bases Tecnológicas } & Carga Horária \\
\hline Técnica de Comunicação & 40 \\
\hline Relações Interpessoais & 40 \\
\hline Geografia Aplicada ao Lazer e Meio Ambiente & 40 \\
\hline História Regional & 40 \\
\hline Francês Instrumental & 40 \\
\hline Informática Básica & 40 \\
\hline Ética e Legislação Aplicada ao Lazer & 40 \\
\hline Contabilidade & 40 \\
\hline Introdução ao Lazer & 40 \\
\hline Primeiros Socorros e Saúde e Segurança no Trabalho & 40 \\
\hline Práticas de Campo & 40 \\
\hline Carga Horária Total do Bloco & $\mathbf{4 4 0}$ \\
\hline
\end{tabular}

Fonte: Projeto PPP-Lazer (Amapá, 2007).

\section{Quadro 2 - Grade Curricular referente ao Módulo II}

\begin{tabular}{|l|c|}
\hline \multicolumn{2}{|c|}{ II Módulo de Competências - Monitor de Lazer e Recreação } \\
\hline \multicolumn{1}{|c|}{ Bases Tecnológicas } & Carga Horária \\
\hline Sociologia do Lazer & 40 \\
\hline Técnicas de Lazer & 60 \\
\hline Manifestação da Cultura Popular & 40 \\
\hline Empreendedorismo Aplicado ao Lazer & 40 \\
\hline Plano de Negócios & 40 \\
\hline Organização e Marketing de Eventos de Lazer & 40 \\
\hline Inglês Instrumental & 40 \\
\hline Gestão de Planejamento do Lazer & 60 \\
\hline Prática em Lazer & 40 \\
\hline Carga Horária Total do Bloco & 400 \\
\hline
\end{tabular}

Fonte: Projeto PPP-Lazer. (Amapá, 2007).

A mesma clareza não existe quanto ao processo de atuação de um auxiliar de recreação e de um técnico em lazer, até mesmo o corpo docente tem dificuldades em entender tal diferenciação. O que identificamos nos discursos é que, para o auxiliar de recreação, a carga horária é menor, assim como o aprofundamento de conhecimentos. Diante disso, o auxiliar teria a "função" de "acompanhar" o profissional de lazer sem poder desenvolver as ações de forma autônoma.

A dificuldade se estende à falta de clareza sobre os termos "lazer" e "recreação": entendemos que não são sinônimos e guardam suas devidas proporções, apesar da ligação historicamente construída entre eles. 
Na matriz curricular da instituição analisada, eles não são entendidos como sinônimos, mas sim de forma hierárquica, ou seja, primeiro a recreação com seus conteúdos básicos e depois o lazer com os conteúdos mais elaborados, como se a "recreação" fosse um pré-requisito para o aprofundamento dos conhecimentos em lazer.

Outro fator que destacamos diz respeito às modificações referentes à matriz curricular do curso. Os entrevistados alegam que podem intervir sugerindo alterações, seguindo alguns critérios, o que se pode confirmar no depoimento do entrevistado 7:

\begin{abstract}
Nós já fizemos duas reformulações no planejamento do curso. Então, com a convivência e com o desenvolvimento do próprio curso, percebemos a necessidade de modificar. Mas todas as alterações são realizadas com o respaldo do Conselho Estadual de Educação. Após a aprovação pelo conselho é que as modificações passam a ser desenvolvidas, já com novas turmas. Pois, a cada seleção de alunos no curso, é obrigatório cumprir as ementas existentes. Quando se sente a necessidade de incluir algo, há flexibilidade no plano da disciplina, então podemos apenas acrescentar, não tirar conteúdo.
\end{abstract}

Nesse ponto, destacamos a autonomia do corpo docente em intervir na seleção dos conteúdos a serem ministrados. Além disso, percebe-se que as alterações advêm no decorrer do processo de formação com base no contato com os discentes, como identificamos na fala do entrevistado 4: "Porque, às vezes, o que está lá nesse conteúdo programático não condiz muito com a realidade daquela turma, dos objetivos que a gente quer atingir".

Uma das entrevistadas destaca o processo burocrático para possíveis modificações na matriz curricular do curso e afirma que esse percurso é longo e demorado e não acompanha o processo de formação, que é dinâmico:

Porque você sabe que é um grande desafio elaborar um projeto, um plano de curso... Principalmente de curso técnico, porque o nosso segmento - bem, todos os segmentos são dinâmicos - mas o nosso de hospitalidade e lazer é muito dinâmico. Por isso não podemos engessar as bases tecnológicas e os conteúdos. Porque quando você elabora um plano desse, e quando você manda para a secretaria de educação, leva um bom tempo para ser analisado lá e depois vai para o conselho também. Então, nesse tempo entre secretaria de educação e conselho para ser aprovado, quando já chega aqui aprovado ele já está desatualizado. É um pouco da burocracia que atrapalha. Por isso que ele tem que ser bem dinâmico. A própria norma jurídica nos protege e diz que podemos mexer. Mas eu tenho liberdade para mexer no conteúdo programático. Ele não pode ser amarrado, engessado. (Entrevistado 2).

Nesse sentido, ressaltamos a dinamicidade do currículo a partir do contexto em questão. Consideramos que esses pontos não devam ser ignorados, uma vez que acreditamos que fatores sociais, culturais, econômicos, entre outros, influenciam na seleção de saberes. 
Como vimos, apesar de estar subordinado ao conselho de educação estadual, o corpo docente tem a liberdade de promover alterações no conteúdo programático, como podemos inferir da fala do entrevistado 9:

Sim. Tive a oportunidade de trabalhar na matriz curricular. Eu identifiquei que as disciplinas Sociologia do Lazer e Técnica de Lazer possuíam conteúdos muito semelhantes, chegando a se tornar repetitivos. Comuniquei isso ao coordenador do curso técnico de lazer e sentamos para trabalhar nessa matriz e resolver a situação.

É nítida a preocupação dos professores com os componentes curriculares a serem abordados; afinal, eles acreditam na relação estabelecida entre esses componentes e o perfil profissional a ser formado. Mais uma vez identificamos a influência dos conhecimentos curriculares selecionando e delimitando saberes:

Evidentemente, se você estiver alterando 100\%, você tem que mandar um outro plano para reformulação. Você pode trocar conteúdo, alterar o conteúdo programático, mas aquilo que eu estava dizendo: quando eu altero o conteúdo programático, eu vou estar alterando o perfil que está lá dentro do plano do curso. Porque o perfil vai sair de acordo com que foi aprovado pela norma jurídica. (Entrevistado 2).

Nesse momento, vale lembrar a relação existente entre o currículo oficial e o real (Forquin, 1996). É por meio de cada espaço específico de formação que se constitui o currículo real, pois todo ele é passível de ser reinventado. Afinal, o currículo ganha forma, realmente, durante as aulas ou em outros espaços de ensino. Desse modo, com base na autonomia dos professores, o currículo prescrito ou o real ganha nova possibilidade para desenvolver os conteúdos que lhes fazem sentido, que têm significado e que vão ao encontro de seus valores e concepções de mundo e de sociedade.

\section{Perfil profissional almejado}

Assim como Paraíso (2010, p. 28), acreditamos que "todo currículo quer formar, produzir ou construir um tipo de sujeito". Dessa forma, analisando as entrevistas e os documentos coletados, foi possível perceber que a instituição também possui um perfil profissional almejado que norteia sua organização curricular e fundamenta suas ações.

De acordo com o PPP-Instituição (Amapá, 2010, p. 12), sua missão é a de:

Promover uma educação profissional contextualizada, que oriente o educando na compreensão da sociedade atual, devendo se propor a tarefa de inserir os jovens e adultos nos processos produtivos e na vida social, proporcionando-lhes condições intelectuais e práticas, próprias do homem integral, e oportunizando ao educando e educador uma interação igualitária de cooperação, respeito mútuo e organização em todos os setores, desenvolver propostas éticas e morais para um bom 
relacionamento humano, profissional e responsável. Visando, assim, à construção de uma sociedade que almeja justiça, convivência harmônica e igualdade de oportunidades.

Percebemos que a missão da instituição é bem ampla e idealizadora em relação à formação de sujeitos comprometidos não só com as questões profissionais, como também com as de responsabilidade cidadã. Essa concepção vai ao encontro dos argumentos de autores da educação profissional, como Oliveira (2000), Frigoto (2001) e Ferreti (2000), e de autores do lazer, por exemplo, Marcellino (1995) e Paraíso (2010), que vislumbram uma formação para além das habilidades técnicas. Desse modo, ao ampliar o processo de formação não tendo como norte somente a demanda do mercado de trabalho, há possibilidade de se construírem sujeitos atentos à dinâmica da sociedade, que nem sempre é justa. Afinal, é preciso olhar o contexto em que vivemos de diferentes ângulos, para dar conta da totalidade. O saber de forma isolada não permite esse exercício de complexidade entre os fatores políticos, econômicos, sociais e culturais do cotidiano.

Essa concepção de ensino para além das questões de mercado foi notada na fala do entrevistado 6, quando questionado sobre suas concepções de formação profissional:

Um pouco de embasamento teórico, mas que também saiba fazer o que ele está se propondo: a questão do lazer em si. E também formar uma pessoa consciente, uma pessoa politizada, uma pessoa que tenha uma visão de mundo mais clara das coisas, não só dentro do campo dele, mas também abrangendo todos os aspectos da vida em si.

No entanto, no decorrer do texto que constitui o PPP-Instituição, a preocupação com uma formação profissional voltada para atender a demanda do mercado de trabalho sobressai. No intuito de justificar a importância da instituição, o documento apresenta trechos como: "o mercado está mais exigente e mais competitivo, e a geração de empregos requer pessoas capacitadas, criativas, íntegras e melhor preparadas para o mundo do trabalho" (Amapá, 2010, p. 14), e "na perspectiva de responder às exigências do mundo produtivo, a instituição organizou o curso técnico em lazer com uma carga horária total de 840 horas" (Amapá, 2010, p. 11). Além disso, essa concepção também pode ser identificada no objetivo específico do curso:

Assim é o que se propõe o Centro de Educação Profissional do Amapá (Cepa), através da oferta do curso de nível técnico profissional - técnico em lazer, com um currículo voltado para atender as exigências de qualificação e/ou habilitação profissional para o mercado de trabalho. (Amapá, 2007, p. 5).

Na fala do entrevistado 2, também fica nítido o objetivo prioritário da formação profissional: "Aqui você prepara mais para o mercado de trabalho. É técnico para quê? Para o mercado de trabalho. Então, o foco é a qualidade dentro do quê? Dentro do mundo do trabalho." 
Nesse ponto, é preciso ponderar o fato de o mercado ser o regulador do ensino. Assim como Silva (2000), pensamos que a relação entre o espaço de formação e o mercado de trabalho deva existir, porém de forma "equilibrada", de modo que um não se sobreponha ao outro. Para Silva (2000, p. 184), as instituições de ensino e o mercado são determinantes e determinados um pelo outro, por isso, "não podemos nos tornar míopes para as necessidades que o mercado de trabalho aponta, como também não podemos nos submeter acriticamente a esse mercado".

\section{Concepção de lazer e concepção sobre a ação profissional no lazer}

Em relação ao trato com o lazer no interior do currículo, destacamos o texto do PPP-Lazer, que apresenta três compreensões sobre a temática: a primeira, que o entende como um direito social relacionado à necessidade humana; a segunda, que enfatiza o lazer como um produto com potencial a ser comercializado; e, por fim, a visão dele como um recurso para a melhoria da saúde e da qualidade de vida:

Lazer é um direito humano básico, como educação, trabalho e saúde, e ninguém deverá ser privado desse direito por discriminação de sexo, orientação sexual, idade, raça, religião, credo, saúde, deficiência física ou situação econômica. (Amapá, 2007, p. 6).

Lazer promove a saúde e o bem-estar geral, oferecendo uma variedade de oportunidades que possibilitam aos indivíduos e grupos escolherem atividades e experiência que se adequem às suas próprias necessidades, interesses e preferências. As pessoas atingem seu pleno potencial de lazer quando estão envolvidas nas decisões que determinam as condições de seu lazer. (Amapá, 2007, p. 6).

De acordo com Marcellino (2001, p. 5), existem duas formas antagônicas para se abordar o lazer: "uma que enxerga o lazer cada vez mais como mercadoria, como mero entretenimento a ser consumido, ajudando a suportar, a conviver com uma sociedade injusta e de insatisfação crescente" e outra "que o vê como gerado historicamente na nossa sociedade, e que dela emerge, podendo na sua vivência, gerar também, no plano cultural, valores questionadores da própria ordem estabelecida".

Com base nos trechos acima, verificamos que a concepção da instituição não reduz o lazer a uma mercadoria a ser consumida. Afinal, as concepções de lazer adotadas não só levam em consideração as questões de mercado, como também ressaltam o fenômeno como direito social. Além disso, valoriza-se o princípio da isonomia entre o lazer e os demais direitos sociais, enfatizando as questões culturais, raciais e étnicas.

A preocupação com outras questões propiciadas pelo lazer, não somente as lucrativas, fica explícita no discurso da busca do desenvolvimento pessoal e social, bem como no da promoção da saúde e qualidade de vida por meio das vivências do lazer. Da mesma forma, 
consideram-se as possibilidades diversas do lazer, tendo os sujeitos como coautores de suas próprias vivências.

Lembramos que o lazer é aqui compreendido como uma dimensão cultural da vida humana e um fenômeno complexo e ambíguo que envolve diferentes relações com o tempo e o espaço, manifestando-se nos mais diferentes conteúdos e possibilidades de vivências. Assim como as concepções da instituição, acreditamos que o lazer seja um dos fatores que contribuem para a promoção da saúde e da qualidade de vida dos sujeitos, ao lado de outros aspectos, por exemplo, educação, transporte, moradia, saneamento, acesso aos serviços de saúde, dentre outros. Da mesma forma, consideramos o lazer para além das questões de consumo, como mercadoria e entretenimento. Afinal, acreditamos que ele pode ir além do descanso e do divertimento, pois se caracteriza como um espaço privilegiado para ações que promovam o desenvolvimento social e pessoal dos sujeitos, podendo, mediante sua vivência, despertar sentimentos de cidadania.

A formação profissional proposta pela instituição, quando apontada para as possibilidades de intervenção dos técnicos em lazer, não os reduz a meros executores de atividades de lazer, há, também, uma preocupação em habilitá-los para planejarem, elaborarem e avaliarem tais ações com base em conhecimentos contábeis, jurídicos, administrativos e pedagógicos. Além disso, valoriza-se o aprendizado de diagnósticos e estudos de viabilidade, dando ênfase às questões culturais e identitárias dos sujeitos e aos espaços envolvidos. Esse perfil de formação pode ser identificado nas habilidades propostas pelos conteúdos programáticos de algumas disciplinas.

Assim, ao concluí-las, os alunos devem ser capazes de, por exemplo:

- Interpretar dados jurídicos em relação ao lazer e como forma de solução de problemas existentes (Disciplina: Ética e Legislação Aplicada ao Lazer).

- Identificar, avaliar alternativas de lazer e entretenimento (Disciplina: Sociologia do Lazer).

- Adequar a oferta das manifestações festivas, artísticas, culturais, religiosas, folclóricas e outras aos interesses e expectativas dos turistas, resguardando suas características (Disciplina: Manifestação da Cultura Popular).

- Adequar a oferta aos interesses, hábitos, atitudes e expectativas da clientela; utilizar estudos de viabilidade para a instalação de empresas de prestação de serviços de lazer. (Disciplina: Introdução ao Lazer). (Amapá, 2007, p. 14-34).

Consideramos importante a diversidade de funções conferidas ao técnico em lazer para além do "executar", assim como achamos pertinentes os campos de conhecimentos envolvidos nesse processo de formação. Tal multiplicidade de saberes oferece subsídios para uma ação ampla e fundamentada do profissional do lazer. Nesse sentido, Isayama (2002, p. 209) sugere onze eixos temáticos para nortear o tratamento do lazer nos currículos que formam profissionais para atuarem nesse âmbito e aponta que "esses temas podem ser desdobrados em várias disciplinas 
e ações, buscando subsídios para o aprofundamento de conhecimentos sobre o lazer".

Dessa forma, identificamos que os temas abordados pelo corpo docente no desenvolvimento das disciplinas variam entre conceituação do lazer, ocorrência histórica e relações com trabalho e educação.

Na disciplina Sociologia do Lazer, trabalho conceitos de lazer- recreaçãotempo livre e a diferença entre recreação e lazer. Peço para cada aluno dar o seu conceito e diferenças, em seguida vamos analisar cada um dos conceitos que eles têm, que trazem de suas próprias experiências de vida. Apresento vários conceitos dos estudiosos e exponho para a turma analisar, comparar, avaliar e debater. Trabalho as funções do lazer, sua classificação, a importância para o ser humano. Trabalho em grupos com relações históricas abrangendo lazer, trabalho e educação desde a antiguidade até os dias atuais. (Entrevistado 9).

É importante dizer que o MEC sugere, por meio do Catálogo Nacional de Cursos Técnicos, temas a serem abordados na formação do técnico em lazer, como: técnicas de animação socioculturais; sociologia do lazer; jogos, recreação, brinquedos e brincadeiras; linguagens artísticas; cultura lúdica; educação ambiental; primeiros socorros; e desenvolvimento interpessoal.

O entendimento do lazer para além das aprendizagens de técnicas e a preocupação em abordar conceitos que fundamentam a temática podem ser identificados na fala do entrevistado 4 ao citar teóricos e concepções do lazer:

As tendências que cada um defende a partir de Dumazedier. A gente até acha assim... Muitas vezes, muito funcionalista. Como se fosse uma concepção funcionalista do lazer. O que é funcionalista: mais voltado para o lazer/trabalho, o lazer como um descanso, um lazer como renovação de energia para a produção. Para o trabalho. Se a gente for ver o Dumazedier, é mais voltado para essa questão aí. E outros teóricos que defendem o lazer como necessidade humana. Independente mesmo desse binômio trabalho/lazer, mas uma necessidade humana. Porque até quem não trabalha necessita de lazer, ou seja, que não tenha um emprego, trabalho formal.

Acreditamos que essa abordagem de lazer, comprometida com saberes para além da reprodução de técnicas, acaba por influenciar a organização curricular do curso, a qual refletirá na formação profissional dos sujeitos. Além disso, a abordagem do lazer com base no referencial teórico "possibilita a compreensão da prática por meio de novos olhares, permitindo a consolidação da práxis" (Paraíso, 2010, p. 12). Assim, o reconhecimento do técnico em lazer como profissional qualificado a intervir em diferentes espaços com diferentes públicos pode ser notado na fala do entrevistado 4:

Nós temos várias opções e alternativas. Mas o que, assim, eu vejo é um mercado bem aberto. É mais na questão cultural mesmo. Da cultura, né? Nas atividades culturais, de promoção de artistas culturais, trazerem bandas, cantores, esse tipo de promoção que é muito forte aqui, né? As colônias de férias, que é bem forte: tem a AABB, Sesc, Sesi... Várias entidades aí que promovem essas atividades de lazer de férias, e que 
absorve esses técnicos, monitores e tudo mais... Basicamente isso. Institucionalmente falando nós temos órgãos públicos que trabalham as políticas de lazer: as secretarias, os departamentos também absorvem essa mão de obra especializada.

Por vezes, a visão do profissional do lazer como um possível gestor é destacada na fala dos entrevistados, na tentativa de justificar a importância do curso e de valorizar a área, como se quisesse dizer que esse campo profissional não é só diversão, mas também pode ser algo "sério" e lucrativo:

Na visão da contabilidade, a gente o prepara para caso ele queira abrir a sua empresa... Assim... De eventos... Oferecer o lazer, tudinho, né? Aqui em Amapá tem muitos atrativos, né? Praticamente é abrir a sua empresa para oferecer o seu serviço para a população. (Entrevistado 7).

Com base na concepção de se formar empreendedores é que foi justificada a inclusão de três disciplinas na matriz curricular do curso técnico em lazer: empreendedorismo aplicado ao lazer; plano de negócios; e contabilidade. De acordo com o entrevistado 1, as demais disciplinas seguiram as orientações do MEC:

Incluímos algumas (disciplinas), por exemplo: "empreendedorismo", "plano de negócios", "contabilidade", por nós termos essa liberdade que estava direcionada na cartilha do MEC e as demais já vinham na cartilha como conteúdos e componentes curriculares obrigatórios.

Outro item a ser destacado é a relação estabelecida entre o entendimento sobre lazer e outros campos de conhecimento, como turismo e agenciamento de viagens. Por vezes, esses termos são compreendidos como sinônimos ou de forma hierarquizada. No entanto, concordamos com Araújo e Isayama (2009, p. 145) quando trazem para o debate essa relação:

Pensar as fronteiras e limites entre duas áreas de conhecimento significa estabelecer seus domínios e demarcar seus territórios com certa precisão. No entanto, quando se fala em lazer e turismo, essas fronteiras que reclamam por uma exatidão conceitual, revelam-se espaços de transição, lugares de interpenetrações, campos abertos de interseções, seja em seus aspectos culturais, sociais ou históricos.

O que se configura é uma constante defesa de territórios por parte dos estudiosos de turismo e de lazer, ao afirmarem que o turismo está dentro do lazer ou vice-versa. A fala do entrevistado 4 exemplifica a relação entre esses dois campos de conhecimento:

Nós temos essa disciplina (Sociologia do Lazer) dentro do curso técnico de guia de turismo, que se faz necessário. O guia tem que ter noções do que é lazer, porque o turismo também está dentro do lazer como também o lazer está dentro do turismo. Existe até um trocadilho: se turismo é lazer ou lazer é turismo, né? Existe isso aí (risos). Mas na realidade o lazer está dentro do turismo. Nós temos o turismo de lazer. É até uma tipologia do turismo. E em função disso, nós temos procurado trabalhar e estudado um pouco. 
Nesse ponto, entendemos que lazer e turismo estabelecem significativas conexões, porém devem ser abordados de forma distinta. Concordamos com Camargo (2003, p. 36) quando alerta que "nem tudo que é lazer reduz-se ao turismo" e, "por mais que alguns tentem sobrepor ou mesmo reduzir um fenômeno ao outro (lazer/turismo), trata-se de mostrar que ambos se recortam mutuamente, guardando um núcleo comum, mas conservando subáreas autônomas". O desafio seria, portanto, "deixar de se conceber as interfaces entre turismo e lazer como um preciso limite entre eles, para se entender que elas são espaços vagos, de interpenetração e mistura entre essas duas áreas" (Araújo; Isayama, 2009, p. 149).

\section{Relações teoria e prática}

A atuação e a formação dos profissionais técnicos e graduados em lazer são marcadas pela falta de clareza na definição da identidade profissional e na delimitação de saberes. Dessa forma, as características de cada um acabam se justificando pela carga horária e pela possibilidade de aprofundamento na temática.

Diante das análises das entrevistas, percebemos que a diferenciação entre técnico e graduado muitas vezes recai sobre a dicotomia "braçal/ intelectual", a qual considera o primeiro como o responsável pelas tarefas práticas e o segundo, pelas tarefas teóricas e científicas, ou ainda considera que os técnicos estariam subordinados aos profissionais graduados:

A diferença está... Eu acredito que está na atuação. Na atuação. Vamos dizer assim: onde que esse profissional vai atuar. O seu espaço de atuação. Então o técnico a gente percebe e é muito claro, nesse perfil desse profissional, que o técnico é mais específico. Ele trabalha numa área mais específica. Não é um generalista. Ele é mais especialista, né? Já graduação é mais abrangente essa área de atuação por conta do conhecimento que ele recebe. Ele é mais generalista e pode atuar em vários setores dessa categoria profissional. Então um técnico em lazer é... Na área de desporto, por exemplo, o técnico é mais especializado para atuar naquele setor. Já um graduado... Tem um outro conceito que a gente usa e que as pessoas falam e que faz até sentido para a gente fazer uma certa diferenciação: é que o técnico seria para uma atividade única, porque ele está lá em um setor específico, e o graduado, seria mais o gestor, né? Mas na questão da gestão, do todo, de coordenação de uma instituição, de um setor macro, né? E o técnico estaria dentro de um setor específico. (Entrevistado 4).

Além disso, vale lembrar que a concepção de ensino baseada nessa dicotomia "instrumental/intelectual", em que um pensa e o outro executa, se assemelha à configuração de ensino dos períodos pós-escravidão e de industrialização do Brasil, em que o processo de formação foi claramente dividido em duas trajetórias: um ensino para as elites e outro para as classes abastadas (Kuenzer, 1999; Cunha, 2000).

É preciso ficar atento para não se reduzir o ensino técnico a conhecimento, produção e reprodução de técnicas e habilidades, nem 
mesmo isolar os conhecimentos do lazer de outros domínios da realidade, inibindo o exercício da cidadania (Marcellino, 1995). Para tanto, é preciso estimular uma formação calcada pela articulação da teoria e da prática, sem que uma se sobreponha a outra.

Acreditamos ser um equívoco desconsiderar os "saberes teóricos" na formação dos profissionais técnicos. É preciso ficar atento para não se reproduzir a ideia de que, para intervir no campo do lazer, não é necessária a fundamentação teórica. Caso isso aconteça, pode-se restringir a formação dos sujeitos, correndo um sério risco de "colocar" no mercado de trabalho os "especialistas tradicionais" (Marcellino, 1995), prontos para exercerem uma "pedagogia padronizada" (Giroux; Mclaren, 1995).

Essa dicotomia fica explícita no depoimento do entrevistado 8, como se os conhecimentos teóricos caracterizassem os cursos de graduação e os práticos, os cursos técnicos:

A diferença do técnico para o graduado é mesmo a questão do fazer. Então um técnico vem se formar para o saber-fazer. Já a graduação, ela vem te dando é... Várias bibliografias... A graduação vem formar o profissional no sentido mesmo de... Além de mercado... Mas na questão mesmo da teoria e prática.

Consideramos que as diferenças entre um técnico e um graduado em lazer se restringem a alguns fatores: tempo de formação, que varia de 800 a 1.200 horas para um técnico e de 3 a 6 anos para um graduado, iniciativas de pesquisa e extensão nos cursos de graduação, além da possibilidade de ingresso na pós-graduação após a conclusão do curso superior. Ao comparar as funções e as possibilidades de intervenções atribuídas a esses profissionais, não se percebem diferenças significativas, ou seja, as funções de planejar, avaliar, organizar e executar, por exemplo, são as mesmas para técnicos e graduados. Da mesma forma, as possibilidades de intervenção do lazer em setores privados, públicos e no terceiro setor são bem parecidas para os dois profissionais, salvo o ingresso em um cargo específico que exija formação em nível superior.

Com base em documentos e depoimentos, percebemos que a formação profissional do Cepa valoriza a aprendizagem por meio do fazer. O curto tempo de formação (um ano) acaba por priorizar estratégias de ensino voltadas para a resolução de problemas, aproximando as competências e a habilidade da realidade. Para que isso aconteça, diferentes metodologias são criadas, como podemos verificar no trecho abaixo:

O eixo do currículo é essencialmente composto de projetos, problemas e desafios reais e/ou simulados do contexto produtivo, que desencadeiam ações resolutivas. As disciplinas expressas na matriz curricular são referências que contemplam as bases tecnológicas de suporte, trabalhadas pedagogicamente num conjunto integrado e articulado de situação-meio, como a utilização de seminários, ciclo de debates, atividades experimentais, laboratoriais, pesquisas e outros, propostos, monitorados e orientados pelos professores, para o desenvolvimento das competências gerais e específicas da habilitação, que se traduzem em aprendizagens profissionais significativas, desempenho eficiente e eficaz. (Amapá, 2007, p. 12). 
Essa concepção de ensino pode contribuir para a formação de profissionais limitados à execução de programas e ações de lazer. Compreendemos que a formação profissional em lazer, independentemente do nível de ensino, deva contemplar os saberes estabelecendo a relação teoria-prática, sem que um se sobressaia ao outro, na busca de sujeitos críticos capazes não apenas de executarem ações no âmbito do lazer, mas também de entender o contexto, para, a partir disso, elaborar, planejar, coordenar e avaliar a intervenção. Porém, questionamo-nos se, no prazo de um ano, isso seria possível.

De fato, a proposta de ensino do Cepa visa superar a dicotomia teoriaprática na tentativa de formar profissionais comprometidos não só com o mundo do trabalho, mas também com a cidadania. Esse posicionamento é evidenciado em alguns trechos do PPP-Lazer (Amapá, 2007, p. 5):

\begin{abstract}
Uma das formas de dar resposta às exigências do mundo produtivo consiste em formar profissional - técnico em lazer - socialmente responsável, com forte base humanística aliada à necessária preparação teórico-prática, possibilitando um desempenho eficiente frente às necessidades emergentes do mundo laboral. É imperativo que estejam devidamente preparados para o trabalho e para o exercício da cidadania, para tanto, precisam ser trabalhadores diferentes, ecléticos, dinâmicos, com bom conhecimento técnico, críticos e criativos.
\end{abstract}

No contato com os documentos curriculares, percebemos que há uma tentativa, por parte da instituição, em romper com a dicotomia teoriaprática, priorizando o ensino por meio do processo do "saber-fazer", baseando-se no exercício da profissão, como propõe Tardif (2008). Tais iniciativas podem ser identificadas pelas denominações das disciplinas como geografia aplicada ao lazer e ao meio ambiente; ética e legislação aplicada ao lazer; e empreendedorismo aplicado ao lazer - e ainda pelos objetivos propostos por algumas disciplinas, por exemplo: elaborar projetos de lazer; organizar a gestão e a operacionalização de eventos; e pesquisar e visualizar oportunidades de lazer como forma de observar e descobrir caminhos que se identifiquem com a peculiaridade regional.

Porém, a proposta de romper com a dicotomia teoria-prática se depara com algumas contradições, por exemplo, os planos de ensino das disciplinas, que são divididos em competências e habilidades. De acordo com o PPP-Lazer (Amapá, 2007, p. 12), as "competências" e as "habilidades" são consideradas como conhecimento teórico e conhecimento prático, respectivamente:

A estrutura curricular enseja permanentemente uma relação dialógica entre as diversas funções, articulando fundamentos teóricos que embasam a relação entre o conhecimento com sua múltipla aplicabilidade prática na vivência ocupacional.

Da mesma forma, o plano de ensino é composto pelas "bases tecnológicas" que são estabelecidas considerando o perfil profissional que se almeja formar após a conclusão do curso. Para o Cepa (Amapá, 2007, 
p. 12), as "bases tecnológicas não passam de insumos de competências a serem desenvolvidas e construídas nos saberes: saber - saber fazer saber ser".

Chamamos a atenção para dois itens: primeiro, a matriz curricular foi construída a partir de pressupostos do que seria um profissional do lazer, baseados em concepções de um determinado grupo de pessoas que selecionaram e delimitaram os conhecimentos que seriam necessários aprender; o segundo item diz respeito ao entendimento sobre habilidades e competências, que acaba por diferenciar ainda mais os aspectos teóricos dos práticos. Essa concepção pode ser explicitada pela fala do entrevistado 2:

Olha, a gente faz até algumas críticas, porque fazem muita confusão entre competências e habilidades. E eu costumo sempre falar com meus alunos em sala de aula. Eu digo: vamos analisar aqui. Aí eu dou um exemplo: o motorista de carro. Quando nós vamos aprender... que nós queremos tirar nossa carteira de habilitação, nós vamos ficar a par da legislação. Nós estudamos a legislação, a parte teórica. Eu tenho a competência, eu conheço teoricamente e eu sou competente teoricamente. Mas quando eu chego para fazer a prática de habilidade, que eu segurei o carro para dirigir, tudo que eu aprendi... Eu preciso dessa competência para eu ter essa habilidade. Elas estão ali casadinhas. Aí eu segurei e se eu não tiver um bom instrutor do meu lado é difícil eu fazer a aplicabilidade dessa competência com essa habilidade. Habilidade é o saber fazer.

Diante do exposto, consideramos que a organização curricular do curso e as concepções dos docentes enfatizam os conhecimentos técnicos, mas nem por isso as abordagens teóricas deixam de existir.

Outro fator que destacamos diz respeito ao processo de avaliação do curso técnico em lazer, que é baseado na proposta da instituição. Esta entende que a avaliação deva acontecer de forma processual e gradativa, levando em consideração as competências e as habilidades como principais objetivos a serem atingidos. "Dessa forma, a avaliação deverá estar voltada para esses fatores, pessoais e ocupacionais, numa harmonia entre aptidões e características individuais e exigências da ocupação" (Amapá, 2007, p. 35).

De acordo com o documento em questão, a avaliação é acumulativa e o rendimento é expresso em forma de conceitos, com base em critérios pré-estabelecidos, que irão definir a aprovação ou não dos discentes. No intuito de atenderem as normas da instituição, o corpo docente cria diferentes formas avaliativas: elaboração e execução de projetos; relatórios, frequência; e participação e envolvimento.

Então tem alguns critérios dentro da realidade da turma que tem como a gente conduzir a avaliação destes alunos. A gente faz em forma de seminário ou a melhor forma que a gente ache que seja melhor para o aproveitamento do aluno. Prova escrita não. Seminários, projetos que a gente faz o acompanhamento mesmo porque tem que ter a parte prática. A gente tem que fazer uma avaliação para estimular o aluno, motivar para ele também vivenciar a prática para aquilo que ele está estudando. Aí se chega ao resultado que a secretaria escolar quer. (Entrevistado 4). 
Consideramos o método avaliativo adotado coerente com a proposta da instituição, uma vez que se valoriza o processo e não o fim em si mesmo. A relação teoria-prática destaca esse processo de avaliação com base no método de reflexão na ação.

\section{Considerações finais}

Este estudo teve como objetivo a compreensão do perfil de formação de um curso de técnico em lazer, na tentativa de entender que profissional tem sido formado nesse espaço e de que maneira se dá o trato com o lazer no interior desse currículo.

Ao olhar as questões curriculares para além dos conteúdos, métodos e objetivos, foi possível perceber que o currículo do curso de técnico em lazer do Cepa se apresenta com características peculiares que revelam o modo como se lida/pensa o lazer e o profissional que se pretende formar. Identificamos que o perfil de formação do Cepa se caracteriza pela construção de profissionais capazes de atuarem em diferentes segmentos do lazer e exercendo ações variadas, valorizando o comprometimento com as questões históricas e culturais da cidade. A partir disso, espera-se que os profissionais ali formados possam ir além das técnicas e habilidades apreendidas no intuito de conceberem o lazer como um fenômeno envolto em um contexto ambíguo e complexo.

As características que influenciam o currículo em questão estão ligadas a pelo menos quatro fatores: econômico; posicionamento geográfico de Macapá; político; e cultural. O posicionamento ao norte do País, seguido da não existência de rodovias que conectam o Estado do Amapá às demais regiões do Brasil, estabelece, por exemplo, uma barreira para acesso aos espaços de formação em lazer. Se pensarmos que grande parte dos grupos de estudos referentes à temática se concentra no sul e sudeste do País, bem como um maior número de cursos e eventos científicos, os aspectos de deslocamento devem ser levados em consideração em virtude não só dos profissionais em formação, como também da formação continuada do corpo docente. Além disso, as limitações na comunicação também podem ser caracterizadas como uma barreira aos espaços de formação, por exemplo, participação e acesso à lista de discussão na internet, blogs, sites e bibliotecas virtuais.

Verificamos que o curso proposto pelo Cepa possui o objetivo principal de formar profissionais para atenderem ao mercado de trabalho. Nesse ponto, consideramos que a relação ensino/mercado deva existir, mas sem que um se sobreponha ao outro. Por outro lado, foi possível perceber que a abordagem atribuída ao lazer não se restringe ao conceito de "mercadoria a ser consumida" (Marcellino, 2001), pois o entendimento do lazer como direito social e necessidade humana também foi identificado.

Constatamos que existe uma preocupação em produzir e ministrar conhecimentos para além das competências técnicas no intuito de uma formação cidadã. Consideramos importante essa proposta, já que uma 
formação ampla para além do simples domínio de técnicas pode contribuir para a construção de sujeitos capazes de compreender que as esferas da vida se entrelaçam e comportam análises de diferentes ângulos, que, se olhados de forma isolada, não dão conta de sua totalidade.

Da mesma forma, percebemos que há uma preocupação com as ações do profissional de lazer para além da mera execução, focando também os aspectos de planejamento e avaliação. Por se tratar de um corpo docente multidisciplinar, a formação dos técnicos é contemplada por um currículo que busca trabalhar com conhecimentos de diferentes áreas: ciências contábeis, administrativas, jurídicas e pedagógicas. Assim, o perfil do profissional formado contempla saberes teórico-práticos num viés multidisciplinar, na tentativa de qualificar os discentes para intervirem em diferentes espaços em que as vivências de lazer acontecem.

Acreditamos que uma formação profissional de qualidade para atuar no âmbito do lazer deva estar comprometida com a construção de ampla formação teórico-prática; incentivo à pesquisa; e busca da formação cultural dos sujeitos. Nesse sentido, identificamos algumas iniciativas referentes ao incentivo à pesquisa e à participação e produção científica. Porém, esses aspectos, apesar de serem destacados como importantes, podem não acontecer em função da reduzida carga horária do curso (840 horas).

O Cepa valoriza a aprendizagem por meio do "fazer", e o tempo reduzido para a formação acaba por priorizar estratégias de ensino voltadas para a resolução de problemas, aproximando as competências e as habilidades da realidade. Apesar de existir uma tentativa de minimizar a dicotomia teoria-prática, os dados da pesquisa mostram que os sujeitos associam a ideia da relação "teoria/prática" com a "braçal/intelectual", como se os conhecimentos teóricos caracterizassem os cursos de graduação e os práticos, os cursos técnicos. Entendemos que os "saberes teóricos" não devem ser desconsiderados na formação dos profissionais técnicos, e a análise identificou que o Cepa se preocupa com essa questão, mesmo que, nem sempre, estabelecendo relações com os "saberes práticos".

Um fator a ser ressaltado se refere à identidade profissional. Mesmo não tendo aprofundado na temática no sentido de estabelecer comparações, percebemos que, no geral, não existem diferenças significativas entre técnico e graduado em lazer no que diz respeito às definições das ações profissionais, nem em relação às possibilidades de intervenção de cada um. A diferença se restringe a três fatores: tempo de formação menor para o técnico; existência de projetos de pesquisa e extensão nos cursos de graduação; e possibilidade de ingresso em programa de pós-graduação por parte dos graduados. Porém, na análise das entrevistas percebemos que o corpo docente relaciona o técnico ao trabalho braçal de "ir a campo" e o graduado à parte intelectual das ações. Outro ponto que destacamos é a formação intermediária daqueles que cursam apenas o primeiro módulo e já obtêm o título de "auxiliar de recreação". Essa "categoria" não é compreendida de maneira clara pelo corpo docente da instituição, no que diz respeito às suas características, funções, possibilidades e limites. 
Nesse contexto, consideramos a necessidade de busca de identidade dos profissionais de lazer não só em relação aos cursos técnicos, mas também às outras modalidades de ensino que vêm formando esses profissionais, como os cursos tecnológicos e os de graduação. Entendemos que a característica multidisciplinar do lazer, seguida da busca por uma solidificação do campo, pode ser o principal fator para a construção desse cenário. Por isso, são necessários outros estudos para analisar o perfil e a identidade do profissional de lazer nesses diferentes níveis de formação. Dessa forma, apontamos a importância de estudos comparativos entre essas modalidades de ensino.

Sendo assim, o presente estudo surge como uma reflexão no sentido de ampliar o debate, auxiliar na compreensão da formação profissional em lazer e estimular ações coletivas no processo de construção curricular dos cursos técnicos de lazer.

\section{Referências bibliográficas}

AMAPÁ. Centro de Educação Profissional do Amapá (CEPA). Plano de Curso: técnico em ecoturismo e lazer: [PPP-Lazer]. Amapá: CEPA, 2007.

AMAPÁ. Centro de Educação Profissional do Amapá (CEPA). Projeto Político Pedagógico: a busca de identidade: [PPP-Instituição]. Amapá: CEPA, 2010.

AMAPÁ. Secretaria de Estado da Educação (SEED). Decreto nº 0987, de 16 de março de 2000. Cria o Centro de Educação Profissional do Amapá - CEPA. Plano de Educação Profissional. Macapá, 2000.

AMAPÁ. Secretaria de Estado da Educação (SEED). Portaria nº 0668, de 30 de julho de 2001. Autoriza o funcionamento do Centro de Educação Profissional do Amapá - CEPA. Plano de Educação Profissional.

Macapá, 2001.

ARAÚJO, Marina; ISAYAMA, Hélder F. As fronteiras entre turismo e lazer. In: SEMINÁRIO O LAZER EM DEBATE, 10., 2009, Belo Horizonte. Anais... Belo Horizonte: UFMG/DEF/CELAR, 2009. p.145-150.

BRASIL. Decreto no 2.208, de 17 de abril de 1997. Regulamenta o $\S 2^{\circ}$ do art. 36 e os arts. 39 a 42 da Lei no 9.394, de 20 de dezembro de 1996, que estabelece as diretrizes e bases da educação nacional. Diário Oficial [da] República Federativa do Brasil, Brasília, DF, 18 abr. 1997.

Seção 1, p. 7760.

BRASIL. Decreto $\mathrm{n}^{0} 5.154$, de 23 de julho de 2004. Regulamenta o $\S 2^{\circ}$ do art. 36 e os arts. 39 a 41 da Lei $n^{\circ}$ 9.394, de 20 de dezembro de 
1996, que estabelece as diretrizes e bases da educação nacional, e dá outras providências. Diário Oficial da União, Brasília, DF, 26 jul. 2004. Seção 1, p. 18.

BRASIL. Lei $\mathrm{n}^{\circ}$ 4.024, de 20 de dezembro de 1961. Fixa as diretrizes e bases da educação nacional. Diário Oficial [da] República Federativa do Brasil, Brasília, DF, 27 dez. 1961. Seção 1, p. 11429.

BRASIL. Lei no 5. 692, de 11 de agosto de 1971. Fixa diretrizes e bases para o ensino de $1^{\circ}$ e $2^{\circ}$ graus e dá outras providências. Diário Oficial [da] República Federativa do Brasil, Brasília, DF, 12 ago. 1971. Seção 1, p. 6377.

BRASIL. Lei $\mathrm{n}^{\circ}$ 7.044, de 18 de outubro de 1982. Altera dispositivos da Lei no 5.692, de 11 de agosto de 1971, referentes à profissionalização do ensino do $2^{\circ}$ grau. Diário Oficial [da] República Federativa do Brasil, Brasília, DF, 19 out. 1982. Seção 1, p. 19539.

BRASIL. Lei no 9.394, de 20 de dezembro de 1996. Estabelece as diretrizes e bases da educação nacional. Diário Oficial [da] República Federativa do Brasil, Brasília, DF, 23 dez. 1996. Disponível em: < http:// www.planalto.gov.br/ccivil_03/leis/19394.htm>.

CAMARGO, Luis Octávio de Lima. A pesquisa em lazer na década de 70. In: SEMINÁRIO O LAZER EM DEBATE, 4., 2003, Belo Horizonte. Anais... Belo Horizonte: UFMG/DEF/CELAR, 2003. v. 1, p. 33-45.

CUNHA, Luiz Antônio. O ensino de ofícios artesanais e manufatureiros no Brasil escravocrata. São Paulo: UNESP; Brasília, DF: Flacso, 2000.

FERRETI, Celso João. Mudanças em sistemas educacionais de ensino em face das reformas no ensino médio e no ensino técnico. Educação \& Sociedade, Campinas, v. 21, n. 70, p. 80-99, abr. 2000.

FORQUIN, Jean-Claude. As abordagens sociológicas do currículo: orientações práticas e perspectivas de pesquisa. Educação e Realidade, Porto Alegre, v. 21, n. 1, p. 187-198, 1996.

FRIGOTTO, Gaudêncio. Educação e Trabalho: bases para debater a educação profissional emancipadora. Perspectiva, Florianópolis, v. 19, n. 1, p. 71-87, jan./jun. 2001.

GIROUX, Henry A.; McLAREN, Peter. Formação do professor como uma contra-esfera pública: a pedagogia radical como uma forma de política cultural. In: MOREIRA, Antônio Flávio; SILVA, Tomaz Tadeu da (Orgs.). Currículo, cultura e sociedade. 2. ed. São Paulo: Cortez, 1995. p. 125153. 
GOMES, Christiane Luce; MELO, Victor Andrade de. Lazer no Brasil: trajetória de estudos, possibilidades de pesquisa. Revista Movimento, Porto Alegre, v. 9, n. 1, p. 23-44, 2003.

ISAYAMA, Hélder Ferreira. Recreação e lazer como integrantes de currículos dos cursos de graduação em Educação Física. 2002. Tese (Doutorado em Educação Física) - Faculdade de Educação Física, Universidade Estadual de Campinas, Campinas, 2002.

ISAYAMA, Hélder Ferreira. Um olhar sobre a formação profissional no lazer. Licere, Belo Horizonte, v. 8, n. 1, p. 11-19, 2005.

KRUGER, Edelbert; TAMBARA, Eleomar. O perfil dos alunos do Centro Federal de Educação Tecnológica de Pelotas - CEFET/RS durante a vigência do Decreto 2.208/9. UNIRevista, São Leopoldo, RS, v. 1, n. 2, p. 1-13, 2006.

KUENZER, Acácia Zeneida. A reforma do ensino técnico no Brasil e suas consequências. In: FERRETTI, Celso João; SILVA JÚNIOR, João dos Reis; OLIVEIRA, Maria Rita N. Sales (Org.). Trabalho, formação e currículo: para onde vai a escola?. São Paulo: Xamã, 1999. p. 121-140.

MAIA, Lerson Fernando dos Santos. A formação de técnico em lazer e suas possibilidades de atuação e intervenção em políticas públicas. In: MARCELLINO, Nelson Carvalho (Org.). Formação e desenvolvimento de pessoal em lazer e esporte. Campinas: Papirus, 2003. p. 81-100.

MANFREDI, Silvia Maria. Educação profissional no Brasil. São Paulo: Cortez, 2002.

MARCELLINO, Nelson Carvalho (Org.). Lazer: formação e atuação profissional. Campinas: Papirus, 1995. (Coleção Fazer Lazer).

MARCELLINO, Nelson Carvalho. Políticas de lazer: mercadores ou educadores?: os cínicos bobos da corte. In: (Org.). Lazer e esporte: políticas públicas. Campinas: Autores Associados, 2001. p. 5-29.

MARCELLINO, Nelson Carvalho. A formação e o desenvolvimento de pessoal em políticas públicas de lazer e esporte. In: (Org.). Formação e desenvolvimento de pessoal em lazer e esporte: para atuação em políticas públicas. Campinas: Papirus, 2003. p. 9-17.

OLIVEIRA, Maria Rita Neto Sales. Mudanças no mundo do trabalho: acertos e desacertos na proposta curricular para o ensino médio (Resolução CNE 03/08). Diferenças entre formação técnica e tecnológica. Educação \& Sociedade, Campinas, v. 21, n. 70, p. 40-62, 2000. 
PARAÍSO, Marlucy Alves. Currículo e formação profissional em lazer. In: ISAYAMA, Hélder Ferreira (Org.). Lazer em estudo: currículo e formação profissional. Campinas: Papirus, 2010. cap. 2.

PINTO, Leila Mirtes Santos de Magalhães. Lazer e mercado. Licere, Belo Horizonte, v. 3, n. 1, p. 182-188, 2001.

SILVA, Silvio Ricardo. Lazer e mercado nas universidades. Licere, Belo Horizonte, v. 3, n. 1, p. 182-191, 2000.

SILVA, Tomaz Tadeu da. Documentos de identidade: uma introdução às teorias do currículo. 3. ed. Belo Horizonte: Autêntica, 2009.

STOPPA, Edmur Antonio. Lazer e mercado de trabalho. Licere, Belo Horizonte, v. 3, n. 1, p. 176-181, 2000.

TARDIF, Maurice. Princípios para guiar a aplicação dos programas de formação inicial para o ensino. In: ENCONTRO NACIONAL DE DIDÁTICA E PRÁTICA DE ENSINO (ENDIPE), 14., 2008, Porto Alegre. Anais... Porto Alegre: PUC, 2008. p. 17-41.

TRIVIÑOS, Augusto N. S. Introdução à pesquisa em ciências sociais: a pesquisa qualitativa em educação. São Paulo: Atlas, 1987.

Carla Augusta Nogueira Lima e Santos, mestre em Lazer pela Universidade Federal de Minas Gerais (UFMG), é docente no Centro Universitário de Sete Lagoas (Unifemm), Minas Gerais, Brasil. Atualmente é membro da Secretaria do Colégio Brasileiro de Ciências do Esporte/ Minas Gerais.

carlaugusta@yahoo.com

Hélder Ferreira Isayama, doutor em Educação Física pela Universidade Estadual de Campinas (Unicamp), é professor do Programa de Mestrado em Lazer da Universidade Federal de Minas Gerais (UFMG), Belo Horizonte, Minas Gerais, Brasil.

helderisayama@yahoo.com.br

Recebido em 26 de abril de 2013.

Aprovado em 25 de fevereiro de 2014. 